See discussions, stats, and author profiles for this publication at: https://www.researchgate.net/publication/46267744

\title{
The Differential Effect of Instructions on Dysphoric and Nondysphoric Persons
}

Article in The Psychological record · January 2010

DOI: $10.1007 / \mathrm{BF} 03395594 \cdot$ Source: OAI

CITATIONS

30

5 authors, including:

Jonathan Kanter

University of Washington Seattle

139 PUBLICATIONS 4,797 CITATIONS

SEE PROFILE
READS

109

Andrew M Busch

Hennepin Healthcare

82 PUBLICATIONS 2,611 CITATIONS

SEE PROFILE 


\title{
THE DIFFERENTIAL EFFECT OF INSTRUCTIONS ON DYSPHORIC AND NONDYSPHORIC PERSONS
}

\author{
DAVID E. BARUCH, JONATHAN W. KANTER, \\ ANDREW M. BUSCH, and JOSEPH V. RICHARDSON \\ University of Wisconsin-Milwaukee \\ DERMOT BARNES-HOLMES \\ National University of Ireland, Maynooth
}

\begin{abstract}
The experimenters investigated whether dysphoric and nondysphoric persons differentially exhibited the traditional instructioninduced schedule-insensitivity effect (rule-governed behavior). Dysphoric and nondysphoric participants were given instructions to perform a matching-to-sample task (four blocks, 40 trials each). The instructions in the first half of the study were correct and in the second half, incorrect. Participants were assigned to one of two instructional control conditions in which they read the instruction either privately (tracking condition) or out loud to the experimenter (pliance condition). Dysphoric individuals demonstrated greater schedule sensitivity (less rule-governed behavior) than did nondysphoric persons. No other differences were found. Results indicate that deficits in rule-governed behavior may contribute to depression; however, this experiment did not incorporate procedures to directly test the role of rule-governed experiential avoidance.
\end{abstract}

Rule-governed behavior has been defined as actions controlled by means of verbal stimuli (i.e., spoken or written instructions, self-talk, etc.) that describe contingencies of reinforcement (Skinner, 1953, 1969), and researchers have attempted to describe differences between behaviors controlled directly by contingencies and rule-governed behaviors controlled indirectly with descriptions of contingencies (rules). For example, rulegoverned insensitivity to reinforcement contingencies has been studied by providing instructions that are accurate for a time (i.e., following the rule leads to reinforcement) and that then become inaccurate (i.e., following the rule does not lead to reinforcement) due to changes in schedules of reinforcement. These studies have demonstrated that instructions exercise substantial control over behavior, even to the point of creating insensitivity to changes in schedules of reinforcement (Baron, Kaufman, \& Stauber, 1969; Catania, Matthews, \& Shimoff, 1982; Hayes, Brownstein, Zettle, Rosenfarb, \& Korn, 1986; Kaufman, Baron, \& Kopp, 1966; Lippman \& Meyer, 1967; Shimoff, Catania, \& Matthews, 1981; Weiner, 1970).

Address correspondence to Jonathan W. Kanter, P.O. Box 413, Department of Psychology, University of Wisconsin-Milwaukee, Milwaukee, WI, 53211. (E-mail: jkanter@uwm.edu). 
Two competing clinical theories have related rule-governed behavior and depression. First, many psychotherapeutic approaches have conceptualized psychopathology, specifically depression, as related to inaccuracies or deficits in client rule-governed behavior. For example, behavior analytic theorists have understood most forms of cognitive therapy as replacing ineffective and inaccurate rules (e.g., "cognitive distortions") with more accurate rules (e.g., "balanced thoughts"; Poppen, 1989; Zettle \& Hayes, 1982). Similarly, Rehm $(1979,1989)$ and Rehm and Rokke (1988) have argued that depressed persons demonstrate deficits in the ability to generate and follow rules, and his Self-Management Therapy program attempts to improve self-monitoring, self-evaluation, and self-reinforcement skills. In accord with these views are findings that depressed individuals demonstrate increased self-reported preferences for immediate over delayed reinforcement compared with nondepressed persons, suggesting less rule following by depressed individuals (Rehm \& Plakosh, 1975; but see Gaynor, Thomas, \& Lawrence, 1999).

An alternative account posits that depression (and other psychopathology) may result from excessive rule-governed behavior, particularly excessively following rules that dictate experiential avoidance (Hayes, Strosahl, \& Wilson, 1999). Experiential avoidance has been described as an unwillingness to remain in contact with aversive private experiences, followed by attempts to escape or avoid these experiences (Hayes, Wilson, Gifford, Follette, \& Strosahl, 1996). Experimental evidence from several areas suggests that experiential avoidance may underlie many clinical syndromes, including depression (Hayes et al., 1996). In contrast to other approaches such as cognitive therapy that attempt to improve or alter instructional control, Hayes and colleagues (1999) suggest that the therapeutic task is to disrupt rule-governed behavior that supports experiential avoidance (Hayes, Strosahl, \& Wilson).

There is little research on rule-governed schedule insensitivities in depression, and the existing literature is inconclusive. Rosenfarb, Burker, Morris, and Cush (1993) provided instructions (the rule-governed group) or no instructions (the contingency-shaped group) to depressed and nondepressed persons prior to training on a multiple differential-reinforcement-of-low-rate/ fixed-ratio schedule computer task. Midway through the study, contingencies were changed. These authors found that nondepressed participants demonstrated the typical schedule insensitivities found in the literature, while depressed participants demonstrated greater schedule sensitivity and less rule-governed behavior, providing support for Rehm's theory that deficits in rule-governed behavior may contribute to depression.

Findings from McAuliffe (2004) suggest otherwise. As this study is currently unpublished, a detailed description of it follows. Depressed and nondepressed adolescents (as assessed with the Inventory for Depressive Symptomatology; Rush, Giles, Schlesser, Fulton, Weissenburger, \& Burns, 1986) were given one of two instructions (pliance or tracking; see below for explanation) for accurate responding on a matching-to-sample task that midway through the study became inaccurate. Specifically, 
participants were first given a short pretest (10 trials) to screen for adolescents capable of performing the matching-to-sample task, in which participants were instructed to select the most similar of three comparison stimuli relative to the sample stimulus. Thereafter, participants completed four blocks (40 trials per block) of the same task. Participants earned points for selecting the most similar comparison stimulus and lost points for other selections during the first and second blocks. Contingencies were reversed for Blocks 3 and 4 so that points were awarded for selecting the least similar stimulus and points were lost for other responses.

Two different forms of instructions were used to establish pliance and tracking conditions. Tracking has been defined as instances of rule-governed behavior in which following the rule is reinforced by attaining the reinforcer specified by the rule (feeling warm when following the rule "wear your coat and you will feel warm"), while pliance occurs when following the rule is reinforced by the rule giver (e.g., experimenter) for complying with the rule (receiving a reward when following the rule "wear your nice jacket and I will give you candy"; Hayes, Zettle, \& Rosenfarb, 1989). Past research has indicated that pliance may be established simply by making instructions public (Zettle \& Hayes, 1983), suggesting that participants may be more likely to follow rules when the experimenter knows the content of the rule (i.e., the experimenter is aware whether the participant is following the rule). Thus, to establish tracking and pliance, participants in McAuliffe (2004) selected a task instruction from a container and read it either aloud to the experimenter (pliance) or silently (tracking). To further enhance pliance, the pliance instructions also included a statement that the experimenter would be checking the participant's performance. Results indicated no schedule sensitivity differences between depressed and nondepressed persons in the tracking conditions; however, depressed individuals exhibited greater rule-governed behavior in the pliance condition. Thus, unlike Rosenfarb et al. (1993), depressed persons in this study demonstrated more rule-governed behavior and less schedule sensitivity, specifically in the context of social influence, consistent with the notion that depressed individuals show excessive concerns for the views and opinions of others. In fact, the social influence in this study may have been particularly strong because the experimenter was a Catholic priest and schoolteacher, and the participants were Irish Catholic adolescents who attended the school in which the experimenter was employed as a teacher.

The current study was an attempt to replicate the findings from McAuliffe (2004) with another population. Specifically, dysphoric and nondysphoric college undergraduates were recruited as participants and a senior graduate student served as the experimenter. The goals of this study were to explore the broader applicability of the McAuliffe finding and to advance the understanding of the relationship between depression and rule-governed behavior.

Method

\section{Participants}

Participants were 29 undergraduates enrolled in psychology courses 
at the University of Wisconsin-Milwaukee. To determine eligibility for the study, 254 participants were administered the Beck Depression Inventory (BDI; Beck, Ward, Mendelsohn, Mock, \& Erbaugh, 1961). Participants who scored 17 or greater or 2 or less were invited to participate in the study. These participants were readministered the BDI immediately prior to the experimental task. Only participants who scored a 12 or higher on this second administration were included in the dysphoric group $(n=15$; 14 female; mean age $=19.7$ years, $S D=1.8$ ). Likewise, only participants who scored 5 or less on this second administration were included in the nondysphoric group $(n=14 ; 9$ female; mean age $=21.5$ years, $S D=3.1)$. Any participants who switched from dysphoric to nondysphoric or from nondysphoric to dysphoric between the first and second administrations were excluded from analyses. On the day of the experiment, the dysphoric group had a mean BDI score of $18.2(S D=5.6)$, and the nondysphoric group had a mean BDI score of $1.8(S D=1.7)$. All participants received extra credit and were included in a raffle in return for their participation.

\section{Procedure}

Dysphoric and nondysphoric participants were randomly assigned across two variables: instructional control (tracking or pliance) and task instruction (instructed to select the most similar or least similar comparison stimulus on the matching-to-sample task). The task instruction manipulation was designed to control for the nature of the change in contingencies that would occur midway through the experiment: Half the participants would need to switch from selecting the most similar stimulus to selecting the least similar stimulus after the change, while the other half would need to do the opposite. All participants were met by the experimenter, who was a male advanced graduate student wearing a white lab coat, and participants first were readministered the BDI along with a demographic questionnaire. Next, participants were told that they would be selecting one slip of paper from a container, which would provide instructions for how to complete the computer task. Participants were asked not to read the slip of paper until prompted by the instructional control script (provided below) and were given no information regarding the contents of the container.

Task instructions. Instructions were written on slips of paper, which were then folded and placed into one of two containers. One container was filled with instructions that stated, "I want you to select the symbol which is most like the symbol at the top of the screen," and the other container was filled with instructions that stated, "I want you to select the symbol which is least like the symbol at the top of the screen." Participants were presented with only one of the two containers (each filled with identical instructions) and asked to select one slip of paper (one instruction) randomly but to not read it.

Instructional control. After selecting an instruction, the experimenter provided the participants with one of two scripts to read (tracking or pliance). All scripts provided brief instructions to perform the matching- 
to-sample task and described the point system for correct and incorrect responses:

In a moment, the monitor screen will display a number of symbols. One of these symbols will appear in the top center of the screen, and three of the same type of symbols will appear along the bottom of the screen, to the left, middle, and right of the top symbol. Your task is to select one symbol from the three bottom symbols. When you have made your selection, place the curser over the symbol using the mouse and left click.

After you have made your selection the symbols will disappear from the screen and a " +1 " or " -1 " score will appear on the screen denoting a point being either awarded or taken away. Your overall total score will also be displayed on the screen as you move through the tasks. Every point earned will equal a raffle ticket toward a cash lottery.

In the tracking condition, the script then instructed participants,

Now read silently the instruction you have selected and then put it back into the container. The computer task consists of four sessions. When you complete each session, notify me by knocking on my office door so that I can prepare the next session. Please follow the instruction that you just silently read.

In the pliance condition, the script instructed participants,

Before proceeding, read aloud now the instruction you have selected from the container. The computer task consists of four sessions. When you complete each session, notify me by knocking on my office door. I will be checking your performance at the end of each of the four sessions.

\section{Each script concluded identically:}

As the computer task may take between 20 and 25 minutes to complete, you will be given a 3-minute break at the end of each session. There will be no talking during the computer task or between sessions. If you have questions please ask them now or wait to have them answered at the end of the study. Do you have any questions?

At this point, the experimenter asked participants in the tracking condition to replace the slip of paper back into the container without sharing with the experimenter the content of the instructions. For participants in the pliance conditions, the experimenter repeated the instruction out loud and visibly wrote the instructions down on his clipboard. During the pliance condition, prior to preparing the next block of trials, the experimenter quickly yet visibly recorded each participant's point total. During tracking conditions, the experimenter only prepared the next block of trials. Time between blocks was equal across tracking and pliance conditions. 


\section{Computer Task}

The computer task consisted of a matching-to-sample task adopted from McAuliffe (2004). Participants were exposed to four blocks of 40 trials. In each trial, participants were presented one sample stimulus at the top center of the computer screen and three comparison stimuli appeared along the bottom of the screen and to the left, middle, and right of the top symbol. The sample stimulus consisted of three identical symbols (e.g., EEE, 777, $<<<)$ and the three comparison stimuli shared two symbols (e.g., EE+), one symbol (e.g., Em9), and no symbols (e.g., P?>). The left, middle, and right positions of the comparison stimuli were presented in a pseudo-random manner. Participants selected one comparison stimulus using the mouse. In the first two blocks (rule-accurate phase), points were awarded and displayed on the screen for selecting the comparison stimulus that shared two stimuli or no stimuli, depending on the rule ("I want you to select the stimulus most like/least like the symbol at the top of the screen"). In the last two blocks (rule-inaccurate phase), contingencies were changed so that the presentation of points was contingent on responding in a manner opposite to the given instruction and deductions were made for following the previous rule. For example, in the last two blocks, if participants were given a rule to select the most similar stimulus, then choosing the most similar stimulus would be considered an incorrect response and would lead to point loss, whereas choosing the least similar stimulus would be reinforced.

\section{Results}

Table 1 displays the total number of correct responses for each participant during the four blocks of trials. All participants responded accurately on the majority of trials during the first two blocks (rule-accurate phase). Participants performed $98.79 \%(1,146 / 1,160)$ of the trials correctly during Block 1 and performed $99.74 \%(1,157 / 1,160)$ correctly during Block 2. In contrast, during the rule-inaccurate phase, $44.91 \%(521 / 1,160)$ and $45.34 \%(526 / 1,160)$ of responses were correct during Blocks 3 and 4 , respectively. Consequently, it appeared appropriate to use the average number of correct responses from Blocks 3 and 4 for each individual as a measure of rule governance. In addition, as visual inspection of the data reveals, the overall distribution of scores was bimodal and failed to meet assumptions of normality. For that reason, the data were rank-ordered and Mann-Whitney $U$ tests correcting for multiple tie rankings were performed on all analyses reported below.

\section{Task Instruction}

The Mann-Whitney $U$ test was used to compare rule governance (mean accurate responding in Blocks 3 and 4) between participants instructed to select the most similar stimuli and those instructed to select the least similar stimuli. There were no differences between these groups. No significant differences were found when this comparison was 
Table 1

Correct Responses, by Instructional Control Condition and Block, for Dysphoric and Nondysphoric Participants

\begin{tabular}{|c|c|c|c|c|c|c|}
\hline \multirow[b]{2}{*}{ Participant } & \multirow{2}{*}{$\begin{array}{c}\text { Instructional } \\
\text { Control }\end{array}$} & \multirow[b]{2}{*}{ BDI Score } & \multicolumn{4}{|c|}{ Correct Responses, by Block } \\
\hline & & & 1 & 2 & 3 & 4 \\
\hline \multicolumn{7}{|c|}{ Dysphoric Participants $(n=15)$} \\
\hline 5 & Pliance & 25 & 40 & 39 & 11 & 1 \\
\hline 9 & Pliance & 16 & 39 & 40 & 3 & 1 \\
\hline 15 & Pliance & 14 & 40 & 40 & 38 & 39 \\
\hline 19 & Pliance & 17 & 35 & 40 & 28 & 37 \\
\hline 27 & Pliance & 17 & 40 & 39 & 1 & 0 \\
\hline 29 & Pliance & 15 & 40 & 40 & 36 & 40 \\
\hline 35 & Pliance & 18 & 40 & 40 & 39 & 39 \\
\hline 7 & Tracking & 27 & 40 & 40 & 2 & 0 \\
\hline 11 & Tracking & 16 & 39 & 40 & 38 & 38 \\
\hline 14 & Tracking & 15 & 39 & 40 & 38 & 40 \\
\hline 21 & Tracking & 12 & 40 & 40 & 39 & 40 \\
\hline 22 & Tracking & 28 & 40 & 40 & 20 & 21 \\
\hline 25 & Tracking & 14 & 40 & 40 & 36 & 40 \\
\hline 30 & Tracking & 12 & 40 & 40 & 4 & 0 \\
\hline 31 & Tracking & 27 & 40 & 40 & 37 & 39 \\
\hline \multicolumn{7}{|c|}{ Nondysphoric Participants $(n=14)$} \\
\hline 8 & Pliance & 0 & 40 & 40 & 0 & 0 \\
\hline 16 & Pliance & 5 & 39 & 39 & 33 & 31 \\
\hline 18 & Pliance & 2 & 40 & 40 & 3 & 0 \\
\hline 26 & Pliance & 2 & 40 & 40 & 2 & 0 \\
\hline 32 & Pliance & 0 & 39 & 40 & 6 & 0 \\
\hline 33 & Pliance & 5 & 40 & 40 & 0 & 0 \\
\hline 34 & Pliance & 4 & 40 & 40 & 37 & 40 \\
\hline 3 & Tracking & 1 & 40 & 40 & 33 & 40 \\
\hline 4 & Tracking & 0 & 40 & 40 & 0 & 0 \\
\hline 6 & Tracking & 1 & 39 & 40 & 36 & 40 \\
\hline 10 & Tracking & 1 & 39 & 40 & 0 & 0 \\
\hline 17 & Tracking & 1 & 40 & 40 & 0 & 0 \\
\hline 24 & Tracking & 2 & 39 & 40 & 1 & 0 \\
\hline 28 & Tracking & 1 & 39 & 40 & 0 & 0 \\
\hline
\end{tabular}

Note. BDI = Beck Depression Inventory.

restricted to dysphoric, nondysphoric, tracking, and pliance participants. It was concluded that taken together, the two task instructions produced no order effects in the present study, and this variable was collapsed for all further analyses.

\section{Dysphoria and Instructional Control Conditions}

With the Mann-Whitney $U$ test, a significant difference in rule governance between dysphoric participants $(n=15$; sum of ranks $=$ 288.5) and nondysphoric participants $(n=14$; sum of ranks $=146.5)$ was found $(U=41.5, p<01)$. As can be seen in Table 2 , dysphoric participants had a higher median number of correct (schedule-sensitive) responses in Blocks 3 and 4 ( $m d n=38.0$ : semi-interquartile range [SIR] $=18.3)$ compared with nondysphoric participants $(m d n=0.8$; $S I R=$ 
16.6). This finding indicates that dysphoric participants were less rulegoverned compared with nondysphoric participants. The effect was significant within the tracking condition $(U=7.5, p<.05)$, in that dysphoric participants $(n=8$; sum of ranks $=84.5)$ had more correct responses than did nondysphoric participants $(n=7$; sum of ranks $=35.5)$. No significant difference was found within the pliance condition.

Table 2

Correct Responses in Blocks 3 and 4 for Dysphoric and Nondysphoric Participants

\begin{tabular}{lrrrrrrrrr}
\hline Instructional & \multicolumn{3}{c}{ Total } & \multicolumn{3}{c}{ Dysphoric } & \multicolumn{3}{c}{ Nondysphoric } \\
\cline { 2 - 11 } Control & $N$ & $\mathrm{mdn}$ & SIR & $n$ & $\mathrm{mdn}$ & SIR & $n$ & mdn & SIR \\
\hline Overallion & 29 & 6.0 & 18.8 & 15 & 38.0 & 18.3 & 14 & 0.8 & 16.6 \\
Tracking & 15 & 20.5 & 19.0 & 8 & 38.0 & 16.1 & 7 & 0.0 & 18.3 \\
Pliance & 14 & 4.5 & 18.6 & 7 & 32.5 & 18.3 & 7 & 1.5 & 16.0 \\
\hline
\end{tabular}

Note. $\mathrm{mdn}=$ median; $\mathrm{SIR}=$ semi-interquartile range.

To determine whether rule-governed behavior was affected by instructional control conditions (pliance vs. tracking), a series of MannWhitney $U$ tests were conducted, collapsing for and within dysphoric conditions. No significant differences were found between pliance and tracking participants when collapsing for dysphoric status or between pliance and tracking participants within dysphoric or nondysphoric conditions (see Table 2 for median scores).

\section{Discussion}

In the present study, dysphoric participants demonstrated greater schedule sensitivity and less rule-governed behavior than did nondysphoric participants. Manipulations of instructional control (pliance vs. tracking) failed to produce significant differences in rule governance. Instructions led to schedule insensitivity among only the nondysphoric participants; this finding is consistent with the previous literature on rule-governed insensitivity, which has established the insensitivity effect with nonclinical populations (Baron et al., 1969; Catania et al., 1982; Hayes et al., 1986). In addition, the greater schedule sensitivity found among dysphoric participants is consistent with Rosenfarb et al. (1993), who also reported greater schedule sensitivity among depressed participants.

Findings from the present study differ from those of McAuliffe (2004) in that (a) rule-governed schedule insensitivity in dysphoric participants was observed, whereas the present study reports it in nondysphoric participants, and (b) McAuliffe found greater schedule insensitivity among dysphoric participants in the pliance condition, whereas the present study showed no difference between tracking and pliance conditions. The excessive rule governance in the depressed-pliance condition reported by McAuliffe, however, was found with the use of an Irish male adolescent sample and a Catholic priest-teacher experimenter, as opposed to the 
mostly female, undergraduate sample and graduate-student experimenter employed in the current study. It is possible, therefore, that McAuliffe's study evoked high levels of pliance (by using an experimenter who was a strong authority figure among the adolescent participants) and this pliance may have been particularly evocative for depressed participants. Such interaction effects complicate a simple model of rule following and depression but may be important. Furthermore, the nature of the social interaction in the McAuliffe study may be more representative of the kinds of social interactions engaged in by depressed people and may be a better analogue in that sense.

Unlike McAuliffe (2004), the tracking condition in the present study included the request "Please follow the instruction you just silently read." This instruction may have evoked some pliance and thus may have effectively created two pliance conditions with differing levels of strength. In fact, most attempts to create tracking will include some levels of pliance by means of the experimental context (e.g., receiving extra credit or monetary payment in exchange for complying with the experimental procedures). This phenomenon may partially account for the current study's inability to replicate McAuliffe's pliance effect. While the two tracking instructions were slightly different between studies, the pliance conditions were the same (i.e., instructions were read out loud and included a statement that performance would be checked throughout the study). This similarity is significant considering that the main finding in McAuliffe was a significant difference in rule governance between depressed and nondepressed persons in the pliance condition only, which was not found in the present study.

Other differences between the present and McAuliffe (2004) studies may have also accounted for the failure to find a pliance-tracking distinction. First, pliance may be particularly challenging to produce experimentally in college undergraduates in that they may be less inclined in general than adolescents to follow rules. It may also be possible that the public-private manipulation to produce pliance and tracking may produce pliance among adolescents yet not fool undergraduate students (i.e., did participants believe that the instruction was completely private?). Future studies employing such a deception among college students should include a manipulation check to determine whether participants actually believed that their instructions were unknown to the experimenter.

Second, differences in reinforcer value may have played a role in that McAuliffe (2004) provided small yet guaranteed monetary reward while the present study offered raffle tickets for a large yet uncertain monetary reward. Third, differences in how depression was assessed between studies make the groups difficult to compare directly, but comparing McAuliffe's depression criteria with ours suggests that McAuliffe's dysphoric participants may have been more dysphoric than our dysphoric participants. More severe levels of depression may be required for pliance manipulations to show differential effects experimentally. Future research is necessary to explore these issues. 
Nonetheless, our findings, along with those of Rosenfarb et al. (1993), support Rehm's conceptualization that deficits in rule-governed behavior may contribute to depression. These findings appear incongruent with the conceptualization of Hayes and colleagues that excessive rule-governed behavior underlies much of psychopathology. Hayes and colleagues, however, argued that the problem is not excessive rule-governed behavior in general but excessive rule-governed behavior in the service of experiential avoidance (termination or avoidance of aversive private events). Consequently, it may be that the present study failed to directly test this theory. In particular, it would be useful to establish or identify experiential avoidance with respect to specific stimuli and assess for rule-governed insensitivity among depressed and nondepressed persons with respect to those stimuli. From this perspective, one could argue that McAuliffe (2004) created a context for experiential avoidance that led to excessive rule following (i.e., adolescents following an authority figure's instructions to avoid the emotional discomfort created by deliberate noncompliance). Arguably, in conditions such as in the present study and Rosenfarb et al. (1993), in which there may be relatively lower levels of pliance and theoretically less experiential avoidance, it can be expected that depressed participants will display greater schedule sensitivity. Of course, whether this is true or not is an empirical matter.

There were several limitations of the current study. First, participants were identified as dysphoric through self-report measures. Second, the present findings were obtained from a mostly female, undergraduate sample. Third, the sample sizes for the comparisons of dysphoric versus nondysphoric individuals within the pliance and tracking conditions (simple effects) were quite small, limiting power to detect differences. Fourth, as mentioned previously, a manipulation check was not included to assess whether participants believed that the experimenter was unaware of the instruction's contents and whether they suspected that all the instructions in the container were identical. Replications that include a more comprehensive clinical interview to assess dysphoria and depression, a postexperimental manipulation check, and larger and more diverse samples would increase the analytic power and generalizability of the research.

In summary, the current study replicated the lack of rule governance (or increased schedule sensitivity) for dysphoric individuals previously reported by Rosenfarb et al. (1993) and thus failed to reproduce the results reported by McAuliffe (2004), which showed greater pliance for dysphoric than for nondysphoric participants. Although the discrepancy between the current findings and those reported by McAuliffe remain a source of speculation, the data are important because they highlight that the relationship between rule following and depression may be quite complex, and thus it requires further empirical analysis. Specifically, the failure to find an effect for instructional control (pliance vs. tracking) may have been due to the inability to find a rule giver with stimulus properties of sufficient strength to evoke measurable pliance. Perhaps future studies could explore the effects of different levels 
of pliance on the performances of dysphoric and nondysphoric persons. For example, would pliance and tracking produce different outcomes if the experimenter sat beside the participant during the pliance condition and provided occasional verbal reinforcers for pliance-consistent responses, and would dysphoric and nondysphoric individuals respond differentially to pliance or tracking instructions, or both, under these conditions? The results arising from this type of research may well shed more light on the relationship between rule following and depression. Finally, considering that Hayes and colleagues (1996) have conceptualized that excessive rule governance may underlie not only depression but also psychopathology in general, future studies of comparative levels of rule governance in other clinical populations are necessary.

\section{References}

BARON, A., KAUFMAN, A., \& STAUBER, K. A. (1969). Effects of instructions and reinforcement-feedback on human operant behavior maintained by fixedinterval reinforcement. Journal of the Experimental Analysis of Behavior, 12, 701-712.

BECK, A. T., WARD, C. H., MENDELSOHN, M., MOCK, J., \& ERBAUGH, J. (1961). An inventory for measuring depression. Archives of General Psychiatry, 4, 561-571.

CATANIA, A. C., MATTHEWS, B. A., \& SHIMOFF, E. (1982). Instructed versus shaped human verbal behavior: Interactions with non-verbal responding. Journal of the Experimental Analysis of Behavior, 38, 233-248.

GAYNOR, S. T., THOMAS, A. P., \& LAWRENCE, P. S. (1999). Dysphoric mood and preference for immediate versus delayed monetary reinforcement. Psychological Reports, 84, 1281-1293.

HAYES, S. C., BROWNSTEIN, A. J., ZETTLE, R. D., ROSENFARB, I., \& KORN, Z. (1986). Rule-governed behavior and sensitivity to changing consequences of responding. Journal of the Experimental Analysis of Behavior, 45, 237-256.

HAYES, S. C., STROSAHL, K. D., \& WILSON, K. G. (1999). Acceptance and commitment therapy: An experiential approach to behavior change. New York: Guilford Press.

HAYES, S. C., WILSON, K. G., GIFFORD, E. V., FOLLETTE, V. M., \& STROSAHL, K. D. (1996). Experiential avoidance and behavioral disorders: A functional dimensional approach to diagnosis and treatment. Journal of Consulting and Clinical Psychology, 64, 1152-1168.

HAYES, S. C., ZETTLE, R. D., \& ROSENFARB, I. (1989). Rule-following. In S. C. Hayes (Ed.), Rule-governed behavior: Cognition, contingencies, and instructional control (pp. 191-220). New York: Plenum Press.

KAUFMAN, A., BARON, A., \& KOPP, R. E. (1966). Some effects of instructions on human operant behavior. Psychonomic Monograph Supplements, 1, 243-250.

LIPPMAN, L. G., \& MEYER, M. E. (1967). Fixed interval performance as related to instructions and to subjects' verbalizations of the contingency. Psychonomic Science, 8, 135-136. 
MCAULIFFE, D. (2004). Rule-following and depressive symtomology in an adolescent population. Unpublished doctoral dissertation, National University of Ireland-Maynooth, Co., Kildare.

POPPEN, R. L. (1989). Some clinical implications of rule-governed behavior. In S. C. Hayes (Ed.), Rule-governed behavior: Cognition, contingencies, and instructional control (pp. 325-357). New York: Plenum Press.

REHM, L. P. (1979). A comparison of self-control and assertion skills treatments of depression. Behavior Therapy, 10, 429-442.

REHM, L. P. (1989). Behavioral models of anxiety and depression. In P. C. Kendall \& D. Watson (Eds.), Anxiety and depression: Distinctive and overlapping features (pp. 55-79). San Diego: Academic Press.

REHM, L. P., \& PLAKOSH, P. (1975). Preference for immediate reinforcement in depression. Journal of Behavior Therapy and Experimental Psychiatry 6, 101-103.

REHM, L. P., \& ROKKE, P. (1988). Self management therapies. In K. S. Dobson (Ed.), Handbook of cognitive-behavioral therapies (pp. 136-166). New York: Guilford Press.

ROSENFARB, I. S., BURKER, E. J., MORRIS, S. A., \& CUSH, D. T. (1993). Effects of changing contingencies on the behavior of depressed and nondepressed individuals. Journal of Abnormal Psychology, 102, 642-646.

RUSH, A. J., GILES, D. E., SCHLESSER, M. A., FULTON, C. L., WEISSENBURGER, J., \& BURNS, C. (1986). The Inventory for Depressive Symptomatology (IDS): Preliminary findings. Psychiatry Research, 18, 65-87.

SHIMOFF, E., CATANIA, A. C., \& MATTHEWS, B. A. (1981). Uninstructed human responding: Sensitivity of low-rate performance to schedule contingencies. Journal of the Experimental Analysis of Behavior, 36, 207-220.

SKINNER, B. F. (1953). Science and human behavior. New York: Macmillan.

SKINNER, B. F. (1969). Contingencies of reinforcement. New York: AppletonCentury-Crofts.

WEINER, H. (1970). Human behavioral persistence. The Psychological Record, 20, 445-456.

ZETTLE, R. D., \& HAYES, S. C. (1982). Rule-governed behavior: A potential theoretical framework for cognitive-behavioral therapy. In P. C. Kendall (Ed.), Advances in cognitive-behavioral research and therapy (73-118). New York: Academic Press.

ZETTLE, R. D., \& HAYES, S. C. (1983). Effect of social context on the impact of coping self-statements. Psychological Reports, 52, 391-401. 